\title{
Pastoralism, Uncertainty and Resilience: Global Lessons from the Margins
}

\author{
Michele Nori ${ }^{*}$ and lan Scoones $s^{2,3}$
}

\begin{abstract}
This short report describes the PASTRES (Pastoralism, Uncertainty and Resilience: Global Lessons from the Margins) project, its objectives and early implementation. PASTRES investigates the principles inspiring the strategies and the practices applied by pastoralists to tackle and live with and through uncertainties. By engaging in a dialogue with other disciplines, we believe that such principles can be applied to other domains relevant for societal uncertainties, including migration governance, the management of critical infrastructure, financial regulation, epidemic control and others. The project started in late 2017 and this report provides some updates on its development.
\end{abstract}

Keywords: Pastoralism, Uncertainty, Risk, Resilience, Societal challenges, Kenya, China, Sardinia

PASTRES (Pastoralism, Uncertainty and Resilience: Global Lessons from the Margins) is an ERC (European Research Council, Advanced Grant) project hosted by the ESRC (Economic and Social Research Council) STEPS (Social, Technological and Environmental Pathways to Sustainability) Centre at the Institute of Development Studies, University of Sussex, UK, and the European University Institute in Florence, Italy.

Drawing insights from across continents, the project is asking, What lessons can we learn for global challenges from pastoral systems responding to uncertainty? In pastoral regions, we are exploring responses to uncertainty in three areas: environment/resources, markets/commodities and institutions/governance.

The challenge is to draw out wider lessons to inform knowledge and decision-making in other domains where uncertainty is central-including climate and environmental change, financial and commodity markets, disease outbreak response, critical infrastructures, migration policy and security and conflict.

PASTRES has four interlinked objectives:

- Learning from pastoral areas to develop a novel cross-disciplinary theoretical framework for thinking and acting, focused on the relationships between

\footnotetext{
* Correspondence: Michele.Nori@eui.eu

${ }^{1}$ Global Governance Program, European University Institute, Florence, Italy Full list of author information is available at the end of the article
}

uncertainty, resilience and development in the context of rapid change.

- Exploring responses to uncertainties in environment/ resources, commodities/markets and institutions/ governance, and systemic, interlocked relations between these, initially in the three pastoral settings in China, Italy and Kenya, but now extending to others.

- Facilitating a dialogue between marginal pastoral areas and others and drawing out wider lessons for domains where risk and uncertainty are central.

- Developing capacities of a team of researchers and counterparts for policy-engaged, cross-disciplinary research and analysis, and developing a wider network across fields, all exploring uncertainty and resilience.

\section{PASTRES study sites}

The PASTRES project has three core study sites in Africa, Asia and Europe, representing a dryland, montane and island style of pastoralism, each with particular patterns of uncertainty, across environmental/resource, market/commodity and institutional/governance dimensions.

\section{Isiolo, northern Kenya}

Isiolo in Kenya has extensive, dry, lowland areas, populated by mostly Borana pastoralists. Subject to frequent droughts, predicted to increase through climate change impacts, these areas are classic non-equilibrium rangeland systems. However, pastoralism has dramatically changed 
in the area over the last 30 years. There has been a growing privatisation of rangelands, wells and water points, alongside settlement and growth of crop production, and growing marketisation of pastoral products. Systems of pastoral mobility have changed, remaining though central to tackle changing landscapes.

A process of social differentiation has accelerated in the past decades, with significant out-migration from the area, and important gendered impacts. Many Borana pastoralists now combine crop farming with livestock production and are often linked to off-farm activities in small towns. In the last decade, new investors have also been acquiring land in the region, encroaching on irrigable land for large-scale agricultural investments, claiming land for livestock ranching and mining, as well as for investments in renewable energy wind-power schemes and wildlife conservancy schemes. The impacts of the potential Lamu Port-South Sudan-Ethiopia-Transport (LAPSSET) corridor are also felt in the area. The region is in much flux and has been subject to episodic periods of violent conflict over particular 'key resources' for grazing or farming, linked to a process of securitisation.

\section{Qinghai-Tibetan Plateau, western China}

China's rapid economic growth, including development of infrastructure and facilities, towns and cities in the region, has shifted economic incentives, with growing opportunities for out-migration from pastoral areas. There also has been increasing marketisation of yak and sheep production in the Tibetan pastoral system. In addition, state policies have encouraged individualisation and privatisation of rangelands, which has dramatically affected the transhumant montane system.

New institutional structures have been imposed, which encourage a more individualised, settled livelihood, more connected to the market. State-led environmental policies aimed at protecting watersheds and other ecosystem services have encouraged destocking, sedentarisation and the seeking of alternative livelihoods. Some have benefited from these changes, but not everyone.

A process of social differentiation is on-going, with major age and gender consequences. This has resulted in changes in livelihoods, with greater diversification, resulting in pastoral livelihoods more connected to other domains. Responses to marketisation, combined with population pressure, have been varied. In some areas, there have been innovations that aim to reinstate the benefits of communally-managed rangelands, through innovations in the systems based on individual quota. A diversity of systems to access and use rangelands are being set in place by households and communities. Meanwhile, climate change is predicted to result in greater variability in temperature and precipitation as well as local natural disasters, with consequences for both ecology and economics.

\section{Sardinia, Italy}

Sardinia is a major centre for pastoral production in Europe, notably of sheep, but also cattle and horses, involving somewhere transhumant movement to mountain pastures in the summer. Sardinia is a traditional agropastoral society within the Mediterranean setting, where extensive livestock provides important employment and income-earning opportunities. Over the twentieth century, the pastoral economy has undergone many changes, but remains as a main driver of the Sardinian economy, in terms of production and service provision.

Initiated by Roman investors in the late 1800 s, $80 \%$ of Sardinia's famous Pecorino Romano cheese is exported. In recent decades, traditional pastoral systems have undergone important restructuring, with socio-economic and environmental implications, including significant outmigration and changes in ecologies due to shifts in grazing patterns. Increasing fodder and input prices have seen a recent shift back to extensive production.

After a period of crisis, elements of the pastoral system have revived in recent years. New small-scale producers have started up businesses; there is a greater involvement of local youth as well as of a foreign, migrant workforce in herding; the agro-pastoral economy has diversified; and there is an increasing interest in highvalue nature conservation linked to ecotourism, as Sardinian agro-pastoral landscapes and products represent a major attraction for tourists visiting the island.

\section{Further global comparisons}

In addition, through a further three PhD students working with the project, we will also be exploring pastoralism in western India, southern Ethiopia and southern Tunisia. PASTRES research affiliates are additionally working in Benin, Jordan, Kenya, Sicily and Uganda, linking their work to the project (Fig. 1).

\section{Uncertainty as a resource}

Given the harsh and highly variable biophysical settings found in pastoral areas, pastoralists have always lived with, through and from uncertainty. Uncertainty is a resource, essential for livelihoods and at the core of rangeland and livestock management (Scoones 1994; Krätli and Schareika 2010).

Yet pastoral systems the world over are undergoing rapid change. As pastoral economies become linked into globalised networks of trade, as resources in low population density pastoral areas become valued by external investors (whether biodiversity, land, minerals, oil or gas) and as processes of privatisation, individualisation, sedentarisation, territorialisation and emigration extend, 


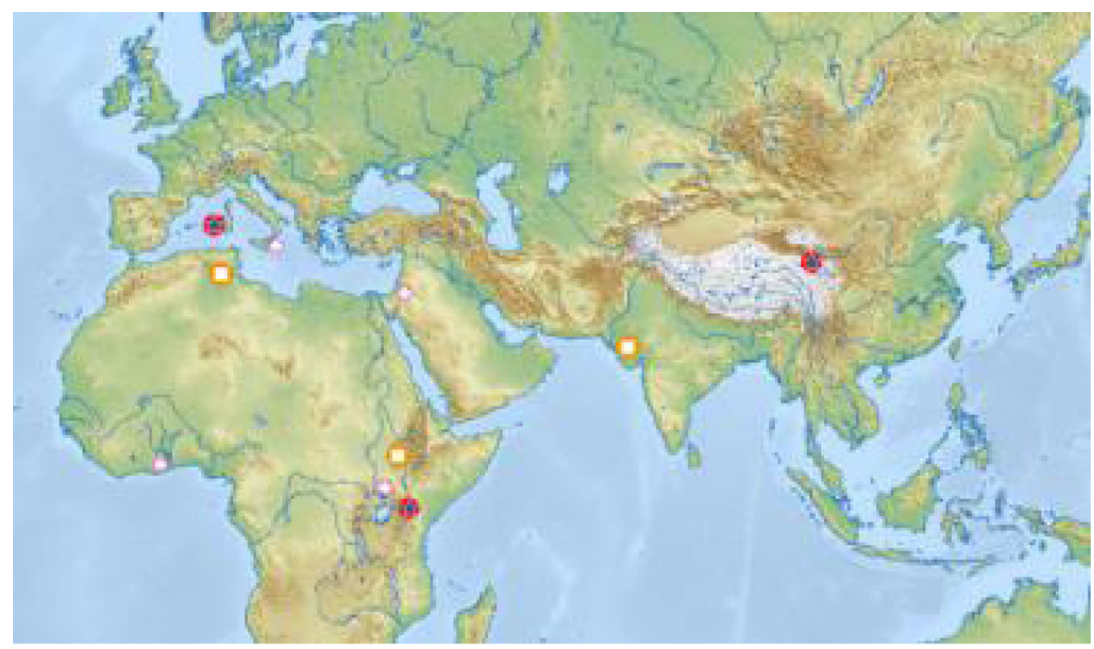

Legend:

\begin{tabular}{|l|l|}
\hline & PASTRES PhD research sites \\
\hline$\square$ & Sites of PASTRES further PhD research \\
\hline$\bigcirc$ & Areas of PASTRES affiliates' activities \\
\hline
\end{tabular}

Fig. 1 PASTRES areas of research and affiliation

pastoral systems are changing, in turn facing new uncertainties. With this, long-standing, traditional systems for responding to uncertainty must change too.

The PASTRES project is exploring responses to uncertainty across three themes. Uncertainties are evident around environment and resources (notably due to climate change and land-use shifts), markets and commodities (including the interplay of informal pastoral economies with high-value export markets) and institutions and governance (linked to enclosures, privatisation and 'hybrid governance' arrangements, including conflict over competing land uses and the wider participation of pastoralists as citizens in national and regional settings). We discuss each briefly below.

\section{Environment and resources}

In complex, non-equilibrium ecological systems, such as the pastoral areas where the project is working, stability conditions rarely apply. This basic insight is often not incorporated into externally-imposed management and policy regimes, resulting in a long history of failure in control-oriented development efforts. Attempts to manage for stability (through certain grazing regimes, fencing systems or environmental management regulations) are upset in highly variable systems. Non-equilibrium approaches, reflecting pastoralists' own flexible, improvised and mobile responses, are required, where variability becomes a resource.

This is especially the case under conditions of climate change, where variability increases and droughts or heavy snowfalls become more frequent. Socio-ecological studies suggest a deeper cultural-political perspective on uncertainty is required; one that links social and technological imaginaries, and deeply-rooted epistemic cultures, to future directions. Approaches for responding to uncertainty and building resilience include 'adaptive management', 'managing mess/generating reliability' and creating 'transformations' (Roe et al. 1998).

\section{Markets and commodities}

The penetration of new capitalist relations through processes of globalisation creates new spaces and interfaces for economic relations. Even in remote pastoral areas, new forms of commodification-of land, water, energy, minerals, carbon, biodiversity and other resources-are occurring. Commodification generates new environmental values, often involving the individualisation and privatisation of resources and the creation of new markets. This restructuring of former common property systems and the enclosure of land and resources can have 
profound effects on livelihoods, specifically for those excluded through such schemes.

As well as 'grabs' by external investors which are central in certain regions, this may involve accumulation by local elites in a process of social differentiation, seen starkly in some pastoral areas. Once at the periphery of the global capitalist economy, rangelands have all over become central to many recent land investment schemes, being that for urbanisation, natural conservation or agricultural production. At the same time, such areas are also seen as sites for carbon sequestration, watershed protection and ecotourism, resulting in conflicts over land use.

As traditional pastoral systems are transformed, new social and political engagements with capital and markets are being forged. Alternatively, they may build on longstanding economic relations, based on a sharing economy, transnational trading, migrant networks and remittance connections. These processes result in evolving cleavages amongst social groups, gender and generations.

While frequently at the margins of state territory and power, pastoral areas are often in the centre of important regional cross-border trade networks. With growing demand for livestock products, driven by increased incomes and changes in urban and middle-class diets, opportunities for pastoral production and commercialisation expand. Yet such market networks are often informal and low value and have to deal with important space and time discontinuities, suggesting important questions about how informal and formal economies intersect under conditions of globalisation.

Indeed, integration into and dependency on market dynamics is a major driver of change in pastoral economies, with herders navigating through livestock production, processing, transportation and commercialisation in very many different forms. 'Real markets' driving change in pastoral areas must be seen as embedded, social-cultural phenomena. Competing processes of economic change, within different frameworks of commodification and market development, occurring in pastoral areas are in turn linked to processes of territorialisation, sedentarisation and state control. This makes pastoral areas sites of conflict between formal and informal markets and between externally driven capitalist expansion and local, endogenous dynamics.

\section{Governance and institutions}

Pastoral areas often are in places at the edge of state power, straddling borders where forms of centralised control are weak and policing costly. Boundaries are fuzzy and contested in mobile systems rooted in forms of common property. In many areas, a new spatial ordering is occurring, linked to processes of territorialisation, sedentarisation, privatisation under neoliberal globalisation, as well as state-led development. In many pastoral regions, simultaneous processes of state-led decentralisation and regionalisation are taking place. Administrative boundaries and border regimes shift, contributing to reconfiguring resource access, territorial networks and power relations.

Processes of incorporation are uneven and may result in displacement, conflict and violence, prompting large-scale movements of people linked to social unrest. As pressures on rangelands are growing, pastoralists are forced to reconfigure their social arrangements and institutional settings, so to better interplay with state authorities, market agents, farming communities, international agencies, urban dwellers and other relevant counterparts. Hybrid governance arrangements are evolving as extensive transhumant systems transform, with a mix of private and common property ownership as well as evolving crossborder connections and networks at regional levels. Changes of authority, political order and new economic agents and forms of citizenship are emerging.

In this fast-changing context, a range of institutional innovations for managing labour, livestock, rangelands and pastoral products exist that respond to uncertainty, and offer important lessons. Standard institutional and governance responses-for example, enforcing boundaries with inflexible management institutions based on settled cultures and practices-fail in pastoral areas and may generate insecurity and conflict, as well as environmental degradation. Authority may be built from below, with networked, hybrid, federated institutions and pluralistic regulations, based in embedded social and cultural relations, bricolage institutions and complex relationships in society, creating local forms of governance and security arrangements that 'go with the grain', without imposing particular forms and rules.

This suggests new thinking about relationships between states, resources, territories and citizens under uncertainty, the range of state and non-state actors involved, and the form of inclusive, adaptive, polycentric, flexible institutions, operating across scales, which are required to build resilience in such settings.

\section{A focus on uncertainty}

How can a deep analysis of pastoral settings, across multiple sites and around these three intersecting dimensions, help us understand uncertainty more broadly? Can a conversation between pastoralism and other domains improve our capacities to respond to the pervasive uncertainties that dominate our everyday life (Scoones 2019)?

Uncertainties emerge as both idiosyncratic shocks, but also systemic stresses-and very often a combination of the two. Yet too often, we do not embrace them; instead, 
we assume we know the array of possible outcomes and their likelihoods and so close down to a focus on risk. This is the argument of Andy Stirling (1999), who identifies three other dimensions of incertitude: uncertainty, where possible outcomes are known, but not their likelihoods; ambiguity, where outcome possibilities are disputed, even if the likelihoods of each are known; and ignorance, where we simply do not know what we do not know. This can be illustrated in a simple heuristic diagram (Fig. 2).

In many settings, closing down to risk is misleading and sometimes dangerous. Navigating the diverse forms of incertitude is essential. But there are professional, methodological, institutional and political processes that run against this. The appraisal methods we use, the models we deploy, the policy measures we apply or the institutions we operate in may end up hiding from view the dynamics of uncertainty.

We argue that 'seeing like a pastoralist' will open up new insights into uncertainty, challenging existing perspectives (Catley et al. 2013). By learning lessons from pastoral societies who live with and indeed from uncertainty, we hope to uncover some of the principles and practices that can help us navigate incertitude in all its dimensions.

Through developing a conversation with other domains where uncertainties are central, we can begin to open up a debate about how to embrace uncertainty in policy and practice to address global uncertainties. Here three examples are offered-finance and banking, critical infrastructures and migratory flows-to illustrate how the connections might be made.

\section{Finance and banking}

In his 2009 paper, Rethinking the Financial Network, Andy Haldane, the Chief Economist of the Bank of England, argued:

Securitisation increased the dimensionality, and thus complexity, of the financial network. Nodes grew in size and interconnections between them multiplied. The financial cat's-cradle became dense and opaque. As a result, the precise source and location of underlying claims became anyone's guess. Follow-the-leader became blind-man's buff. In short, diversification strategies by individual firms generated heightened uncertainty across the system as a whole (Haldane 2009:xx)

The result, he argues, was the global financial crash. With others, he makes the case that we need to rethink regulatory systems and the assumption that individualised firm diversification will increase network stability. Instead, we need to understand networks better, increasing transparency and collective accountability, and focus on people-and their cultures and practices-not just the technical elements. Pastoral systems can tell us a lot about the embedded market and commodity networks and how they manage uncertainties in relation to network structure, regulation, practices and cultures. While finance and banking seems very remote from pastoralism, there is more connection than you might initially think.

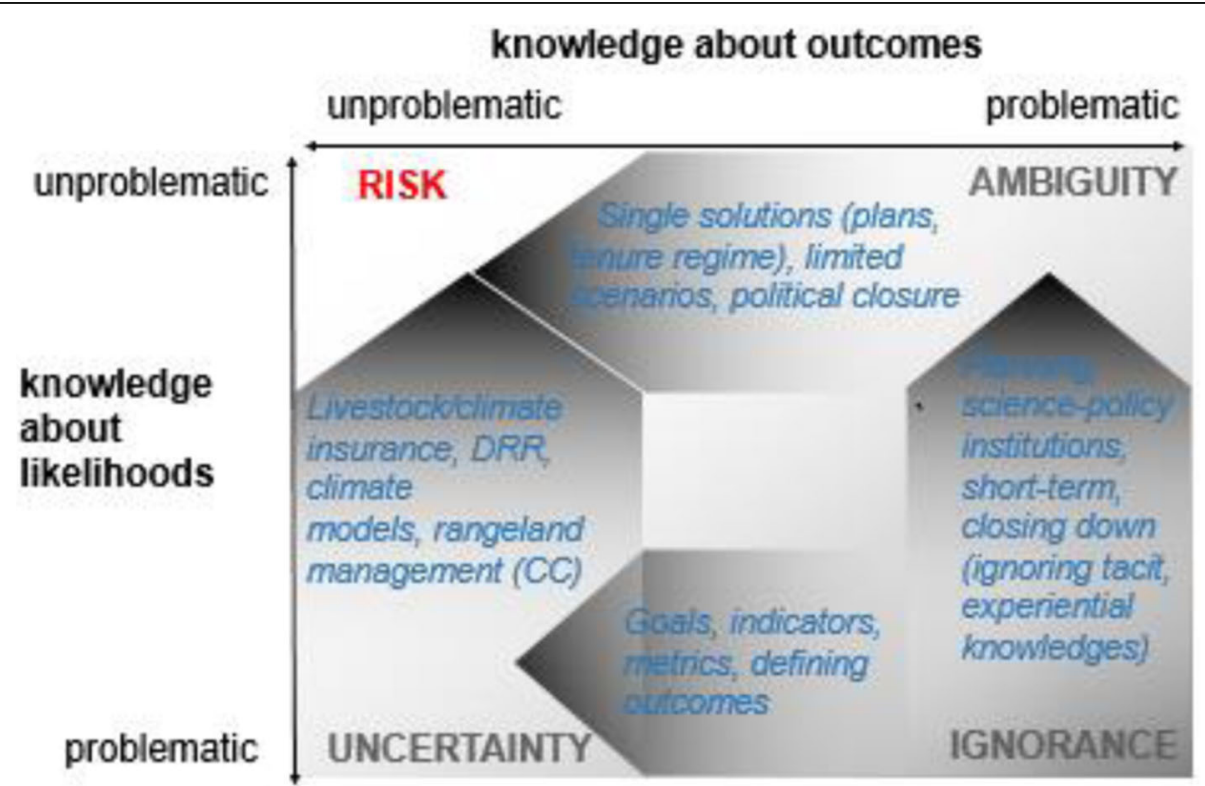

Fig. 2 Closing down: Institutions, practices, politics and power (adapted from Stirling 1999) 


\section{Critical infrastructures}

The same applies to the control rooms of electricity supply systems, nuclear power plants and air traffic control centres. Roe et al. (1998) argue that all are trying to deliver products and services reliably and that system design and management is geared to this aim. Surprisingly perhaps, there are many parallels. Despite an outward appearance of precise engineering design, hierarchical management and top-down control, in practice, reliability in critical infrastructures emerges through the practices of 'reliability professionals'. They are frequently unrecognised and underappreciated, yet offer a crucial role of tracking between on-the-ground realities and wider system changes and can spot problems early and respond to them.

Experimentation, innovation and adaptive response are essential, a theme highlighted in the literature on 'experimental' and 'adaptive' governance (Sabel and Zeitlin 2010). Who then are the reliability managers in pastoral systems, how do they operate, and under what constraints? What lessons can we learn from their practices and experiences for other systems generating reliability under conditions of high uncertainty?

\section{Migratory flows}

Mobility is central for pastoralists' strategies for managing risk and uncertainty, helping to expand social networks to take advantage of opportunities (Nori 2018). Looking at the world through the eyes of pastoralists ensures that mobility is given the centrality it deserves in understanding societal dynamics. For pastoralists, mobility across territories and borders is vital. Complex networks linking kin and others are at the core of market functioning, while flexible movement in response to changing resource availability is essential for escaping crises, threats and risks, including droughts, epidemics and conflicts. Avoiding fixed places for settlement or markets is central to facilitating flexibility and adaptive forms of governance.

Perspectives on mobility challenge policy narratives derived from a settled state perspective, dominated as they are by fixity, settlement, controlled migration, regulated movement, fences and borders. In the same way that settled agrarian states have long reacted negatively to mobile pastoralists, so too states today try and control, order and govern migrants and refugees and other mobile 'outsiders'. Can we learn from pastoralists about how mobility could help responding to the challenges posed by migratory flows? Could there be ways to engage with wider debates about migration, so as to enhance conceptual, methodological and policy dimensions of working with mobile communities?

\section{Conclusion}

It is about 25 years since the rangeland sciences provided an alternative narrative for pastoral resource management, showing how non-equilibrium ecosystem dynamics characterise specific settings, and attesting to the overall 'rationality' of pastoral practices and strategies (Behnke and Scoones 1993; Scoones 1994). Through the PASTRES project, we believe that it is now time to move the challenge further, by demonstrating that pastoralists, their resource management and their livelihood strategies can properly inform understanding and decisionmaking in societal domains that seem increasingly difficult to manage and govern, as degrees of variability and uncertainty are growing and shifting.

PASTRES field research is assessing pastoralists' responses to and strategies for living with and from uncertainties. By doing so, it aims to provide a platform for learning across policy domains and to inform scientists, practitioners and policy-makers about ways to tackle better the intersecting uncertainties that increasingly characterise our societies and economies.

\section{Abbreviations \\ ERC: European Research Council; ESRC: Economic and Social Research Council; LAPSSET: Lamu Port-South Sudan-Ethiopia-Transport; STEPS: Social, Technological and Environmental Pathways to Sustainability}

\section{Acknowledgements \\ This short note is in part derived from the project proposal and the website (pastres.org). It draws on the collective work of many researchers and practitioners, but as a project, briefing is not fully referenced. We acknowledge the funding of the ERC Advanced Grant, whose motto 'high risk, high gain' seems particularly fitting to our endeavour.}

Authors' contributions

Both authors contributed equally to this short report. Both authors read and approved the final manuscript.

Funding

The PASTRES project is financed by an ERC Advanced Grant hosted by the ESRC STEPS Centre at the Institute of Development Studies, University of Sussex, and the European University Institute in Florence.

Availability of data and materials

Data sharing is not applicable to this article as no datasets were generated or analysed during the current study.

Ethics approval and consent to participate Not applicable.

Consent for publication

Not applicable.

Competing interests

The authors declare that they have no competing interests.

Author details

${ }^{1}$ Global Governance Program, European University Institute, Florence, Italy. ${ }^{2}$ Institute of Development Studies, University of Sussex, Brighton, UK. ${ }^{3}$ ESRC STEPS Centre, University of Sussex, Brighton, UK. 
Received: 14 May 2019 Accepted: 6 June 2019

Published online: 25 July 2019

\section{References}

Behnke, R.H., and I. Scoones. 1993. Rethinking range ecology: Implications for rangeland Management in Africa. In Range ecology at disequilibrium, ed. R.H. Behnke, I. Scoones, and C. Kerven. London: Overseas Development Institute Catley, A., and J. Lind. 2013. In Pastoralism and development in Africa: Dynamic change at the margins, ed. I. Scoones. London: Routledge.

Haldane, A. 2009. Rethinking the financial network, https://www.bankofengland. co.uk/speech/2009/rethinking-the-financial-network.

Krätli, S., and N. Schareika. 2010. Living off uncertainty: The intelligent animal production of dryland pastoralists. The European Journal of Development Research 22 (5): 605-622.

Nori, M. 2018. Agriculture and rural territories in the Mediterranean. In: CIHEAM Mediterra 2018. Migration Challenges from the perspective of rural and agricultural inclusive development. CIHEAM, Paris. https://www.ciheam.org/ uploads/attachments/964/12_Med_chap4_EN.pdf.

Sabel, C.F., and J. Zeitlin, eds. 2010. Experimentalist governance in the European Union: Towards a new architecture. Oxford: Oxford University Press.

Scoones, I., ed. 1994. Living with uncertainty: New directions in pastoral development in Africa. London: Intermediate Technology Publications.

Scoones, I. 2019. What is uncertainty and why does it matter? STEPS working paper, 105. Brighton: ESRC STEPS Centre.

Stirling, A.C. 1999. On "precautionary" and "science based" approaches to risk assessment and environmental appraisal. In On science and precaution in the management of technological risk. Vol. II, case studies, ed. A. Klinke, O. Renn, A. Rip, A. Salo, and A. Stirling. Sevilla: European Science and Technology Observatory, report EUR 19056/EN/2, European Commission Joint Research Centre.

\section{Publisher's Note}

Springer Nature remains neutral with regard to jurisdictional claims in published maps and institutional affiliations.

\section{Submit your manuscript to a SpringerOpen ${ }^{\circ}$ journal and benefit from:}

- Convenient online submission

- Rigorous peer review

- Open access: articles freely available online

High visibility within the field

- Retaining the copyright to your article

Submit your next manuscript at $\boldsymbol{\nabla}$ springeropen.com 